DOI: http://dx.doi.org/10.18203/2320-1770.ijrcog20191207

Original Research Article

\title{
Partogram and its relevance in modern obstetrics
}

\author{
Anjali Choudhary*, Meenakshi Tanwar
}

Department of Obstetrics and Gynecology, SGRRIM and HS, Patel Nagar, Dehradun, Uttarakhand, India

Received: 15 February 2019

Accepted: 07 March 2019

*Correspondence:

Dr. Anjali Choudhary,

E-mail: mcgsunil@gmail.com

Copyright: $($ ) the author(s), publisher and licensee Medip Academy. This is an open-access article distributed under the terms of the Creative Commons Attribution Non-Commercial License, which permits unrestricted non-commercial use, distribution, and reproduction in any medium, provided the original work is properly cited.

\section{ABSTRACT}

Background: Normal labor and childbirth is fraught with complexities. In the modern times the child birth has proven to be more challenging than ever. Partogram has proven to be a simple and useful tool in monitoring normal labor. The objective of this endeavor was to site our experiences in using partogram for 'plotting' labors, to assess its utility, limitations and cite controversies.

Methods: Authors analyzed progress of labor plotted on partograms in parturient women to see whether their labor patterns conform to the standard partogram, and can logical conclusions be drawn from their use to decide partogram's utility and applicability.

Results: The use of partogram was not universal and its charting inadequate due to lack of motivation on part of labor room residents, busy labor rooms. When plotted meticulously they showed a wide variation, and many women did not conform to the rates of dilatation of the graph. The use of partogram did not alter the rate of cesarean section for nonprogressive labors with use and non-use of partogram.

Conclusions: Philpott's partogram is a very visual and useful tool to monitor labours and detect labour abnormalities timely. Although it has served as a labour management tool across the labour rooms its use is not universal. There is a plethora of conflicting opinions regarding its utility in modern obstetrics today, ranging from a complete faith in the tool to finding it obsolete and in need of a revision to calling it a medicalization of a natural process.

Keywords: Labor abnormalities, Partogram, Relevance in modern obstetrics, Utility

\section{INTRODUCTION}

Normal labor and childbirth are fraught with complexities. In the modern times the child birth has proven to be more challenging than ever. Partogram has proven to be a simple and useful tool in monitoring normal labor. Time and again it has shown its utility in detecting labor abnormalities and in directing timely interventions. ${ }^{1}$ There is a staggering evidence that peripartum fetal mortality and morbidity is directly related to the labor abnormalities viz asphyxia, birth injuries low Apgar scores and intrapartum or postpartum deaths. About $97 \%$ of all reported neonatal deaths occur in less developed countries. Of these majority are a direct consequence of labor complications. ${ }^{2}$ Careful monitoring and timely recognition of problems are necessary to avoid these outcomes. Non-recognition of labor aberration in time has been the major factor due to which women had dysfunctional labors, primarily due to faults in the passesages, powers or the passenger. These too tardy and too fast labors have repercussion that the fetus and the infant have to suffer.

In order to understand labor abnormalities, it is necessary to understand the course of "normal" human labor. Friedman in 1954 studied the natural course of human labor in 500 primigravidae and proposed a new way of plotting progress of labor in first stage, against time, 
which includes a "latent" phase of labor which begins from the initiation of labor pains till three-centimeter dilatation of the cervix. This phase is devoted entirely to the initial effacement and dilatation of the cervix. After complete effacement and dilatation labor further progresses faster at the rate of $1.3 \mathrm{~cm} /$ hour in primigravidae and $1.5 \mathrm{~cm} /$ hour in multigravida. The second and the most happening phase of labor was termed as "active" phase of labor which comprised of cervical dilatation from $3 \mathrm{~cm}$ to $10 \mathrm{~cm}$ (the 'full' dilatation), -subdivided into three phases-after which labor proceeds to the "second stage" of labor. This is devoted to the actual delivery of the fetus via the birth passage, involving complex mechanisms, perfect coordinations of powers, and the passengers, associated with progressive decent of the fetal presenting part and a series of flexion, rotation and extension movements etc. all work together for the expulsion of the fetus. All of these processes involve a complex mechanism which needed to be finetuned and nuanced to understand different levels where the labor can go wrong.

Freidman very cleverly reduced these complexities into a simple graphical representation of the human labor with its inclusive processes of cervical dilatation decent of the fetal head. He studied parturient primigravidae for the progress of labor and devised a graph of labor depicting cervical dilatation and descent of fetal head in a graphical manner against time, this was known as 'the Friedman's curve' The graph is a sigmoid curve divided into latent and active phase of labor. ${ }^{3}$ The curve later became the basis of the modern 'partogram' that is in clinical use today. The Friedman's Curve has been used as the gold standard for rates of cervical dilation and fetal descent during active labor for the past 47 years..$^{4,5}$

The partograph was designed by Philpott in 1971 in Harare, Zimbabwe. By 1973 the partograph was already considered a simple device used to distinguish normal labor from abnormal labor as it was adopted and used to monitor 15,000 deliveries within 18 months. ${ }^{4}$ World Health organization (WHO) launched the partogram in 1987 as a safe motherhood initiative following a multicentre trial in South Asia that involved 35,484 women (WHO, 1994). ${ }^{5}$ Since the publication of Philpott's study in 1972, the use of partogram has shown to reduce maternal and fetal mortality and morbidity. Philpott's work was inspired by Friedman's cervicograph. ${ }^{6}$

Philpott's Partogram is a graphical representation of the labor events against time, which gives a pictorial overview on the progress of labor and any abnormalities in cervical dilatation and descent of fetal head can be easily noticed. The partogram is designed with action and alert lines usually four hours apart. Any tardy event can be noticed early and corrective actions can be taken. ${ }^{7}$ Many studies over the years have proven efficacy of use of partogram in monitoring labors in low resource settings. Partogram came to symbolize a convenient and simple tool to monitor progress of labor and spot abnormalities as and when they occur, especially in a low resource setting. This was very useful for the midwives employed in conducting labors. They would chart partogram for every parturient woman and inform the obstetrician about the 'The slow labors' or the protracted descent of fetal head, so either augmentation of labor or surgical alternatives could be initiated.

Depending on the various phases of labor in Friedman's curve the labor abnormalities were classified into different categories, the, protraction disorders'- protracted latent phase, protracted dilatation and protracted descent, and arrest disorders -secondary arrest of dilatation and arrest of descent etc.

This practice of using partogram though has proven helpful for many instances raises a few uncomfortable questions, viz, is charting labors on papers medicalizing a natural process? What about the latent phase? the partograms are designed to be plotted during active phase of labor, and if authors include latent phase the labor seems too long, and if latent phase is excluded the, latent phase abnormalities are not detected. Philpott's partogram begins in active phase of labor because he based his study on African women who were admitted in active phase.$^{6,8}$ Do obstetricians and midwives get busy in the paperwork and neglect the patient? If an obstetrician is attendant constantly by the labouring mother's side and monitoring the progress by judiciously timed per vaginal examinations, appreciates the rate of progress, is there a need to chart it on graph? The moot questions that require re-examination is "how relevant is the partogram in modern obstetrics?' Has the Friedman's curve served its utility and needs revision?

Objective of this endeavour was to site our experiences in using partogram for 'plotting labors', to assess its utility and review the literature for recommendations and controversies in its use.

\section{METHODS}

This retrospective study was carried out in a tertiary referral center and medical college. Charting of partograms is mandatory for the record of labor in all parturient women in the institution. Authors reviewed randomly selected seventy-five records of parturient women in labor rooms and obstetrics wards, who had delivered here, to see the level of use of partogram by labor room residents. Authors also enquired the labor room staff about their knowledge regarding use of partogram and its importance.

Authors analyzed progress of labors on partograms in parturient women retrospectively to see whether their labor patterns conformed to the standard partogram, and can logical conclusions be drawn from their use to decide partogram's utility and applicability as a labor management tool. Authors used a questionnaire for residents and labor room staff to enquire frequency of 
partogram use, and technical knowledge, experience and knowledge about importance of its use. Authors surveyed partograms of delivered women for abnormality (slow /Fast labor), and effect on fetus and mother.

\section{Inclusion criteria}

- All the [75 randomly selected] indoor records analyzed were of the women who delivered in our hospital. The records where partograms were charted for women in labor who later needed emergency cesarean section for were also included. Authors considered all 75 postpartum women irrespective of their parity or booking status.

\section{Exclusion criteria}

- Records of the women with antepartum hemorrhage or intrauterine fetal deaths were excluded because the partograms could not be charted completely in these patients.

Observations, information obtained was tabulated and analyzed.

\section{Observations}

- The use of partogram was not universal and its charting sometimes inadequate due to busy labor rooms.

- The charting of partogram when done meticulously required periodic vaginal examination which were poorly timed due to hectic labor rooms and busy staff.

- When plotted religiously they showed a wide variation, and many women did not conform to the rates of dilatation of the standard graph $(1.3 \mathrm{~cm} / \mathrm{hour}$ in primigravida and $1.5 \mathrm{~cm} /$ hour in multigravida, in active phase).

- Many women progressed faster than was anticipated and many women took time despite adequate stimulations to progress but eventually delivered without consequences for the mother or the child.

- The use of partogram did not alter the rate of cesarean section for non-progressive labors with use and nonuse of partogram. Since the appreciation of tardy labor was obvious by regular monitoring in spite of use of partogram.

\section{RESULTS}

Knowledge of partogram charting and its importance among labor room staff was-100\% (All residents and labor room nurses had the knowledge about use and importance of charting).

Review of seventy-five records showed that only $57.33 \%$ had complete charting, out of which many women did not conform to the norms of Friedman's curve (Table 1).
Table 1: Level of charting (75 records).

\begin{tabular}{|l|l|l|}
\hline Category & No. & $\%$ \\
\hline Complete charting of partogram & 43 & 57.33 \\
\hline Incomplete charting & $18^{*}$ & 24 \\
\hline $\begin{array}{l}\text { No charting } \\
\text { Retrospective charting }\end{array}$ & 11 & 14.66 \\
\hline chart after delivery) & 3 & 4 \\
\hline
\end{tabular}

*The partogram was incomplete because these women had cesarean section for non-progress of labor or fetal distress

Some labor progressed faster or slower than the normal curve but all had a favourable outcome. $24 \%$ women needed cesarean section and charting of partogram was incomplete in these women. There were no charts in 11 records (Table 2).

Table 2. Reasons for no charting (11 cases).

\begin{tabular}{|l|l|}
\hline Reason & Number $(\%)$ \\
\hline Busy labour room & $5(45.4 \%)$ \\
\hline Women admitted in advanced labour & $4(36.3 \%)$ \\
\hline Forgot about charting & $2(18.1 \%)$ \\
\hline
\end{tabular}

\section{DISCUSSION}

\section{Relevance of partogram in contemporary practice}

Partogram gives a pictorial view of progress of labor and has been used successfully in many countries to monitor labors and detect deviation in progress of labor. ${ }^{6-8}$ After WHO recommendations it's use became widespread and partogram came to symbolize a simple but effective tool for managing labor. Most of the studies on use of partogram have come from African countries. The partogram is based on the events and phases of Friedman's curve. But since Friedman's time there has been some changes and renewed appreciation in the way a normal labor progress. The curve and later the partogram was designed 47 years ago and a lot has changed since then. The study on which the Friedman's curve was based also is not without problems, the study included 500 primigravid women with an average age of 20 , most women were sedated during labour 117 women were sedated lightly (23\%), 210 were moderately sedated $(42 \%)$ and 164 were deeply sedated 95, (31\%). About $14 \%$ of labours were induced and/or augmented with Pitocin, almost $50 \%$ of babies were delivered by forceps. ${ }^{9}$ All these factors have a potential effect on the progress of a labor and masks or alters the duration and course of a 'normal' labor. Great deal has changed since the index study but same rates of dilatation are considered along with the labour curves, when in actual practice many variations of rates of dilatation are seen in "normal' labor, with variation in labors in primigravidae and multigravida, Induced vs spontaneous labor, augmented vs unstimulated labor and so forth. A practice of charting partogram becomes irrelevant with so many versions of normal labour and the partogram will detect abnormalities far more frequently than is the actual. In 
2014, SMFM and ACOG released a consensus statement called "Safe Prevention of the Primary Caesarean Delivery." In this statement, they re-defined normal and abnormal labour, and stated that Friedman's Curve should no longer be used as the basis for modern labour management (ACOG). ${ }^{9}$ Authors observed many patterns of cervical dilatations in our study, all of which were normal, and women delivered without complications, though their labour did not align to the partogram. There may be an individual yet normal progress of labour in a woman, which is ignored in a method that puts all women in a particular set pattern of rates of labour progression. A study showed that Friedman's curve is an inaccurate description of labor pattern and needs to be revised this study done by Zhang JL, et al on reassessing labour curves on 1329 parturient women concluded that the pattern of labour progression in practice differs significantly from the Friedman curve, and the diagnostic criteria for the protraction and arrest disorders may be too stringent for the nulliparous women. ${ }^{10}$ In our analysis also, the labour curves did not conform to Friedman's curve most of the times.

Another large study conducted on 62000 women in labour, in 19 hospitals across US and observed that there is a wide variation of cervical dilatation, the average labor was much longer than initially thought, and women began their 'active phase' of labor with rapid dilatation after $6 \mathrm{~cm}$. instead of $3 \mathrm{~cm}$ as shown by Friedman. This study concluded that in a large, contemporary population, the rate of cervical dilation accelerated after $6 \mathrm{~cm}$ and progress from 4 to $6 \mathrm{~cm}$ was far slower than previously described. ${ }^{11}$ They saw that the rates of dilatation in multies and primis were similar after $6 \mathrm{~cm}$ dilatation. A recent ACOG guidelines on recommendations for reducing cesarean rate for slow progressing labors has suggested an active phase to begin after $6 \mathrm{~cm}$ dilatation. ${ }^{11}$ ACOG published the Obstetric Care Consensus, "Safe Prevention of the Primary Cesarean Section Delivery," in March 2014, which recommended new guidelines for handling labor. In a study by Tina Lavender et al to determine the effect of portogram design on perinatal and maternal morbidity and mortality, they searched Cochrane Pregnancy and Childbirth Group's Trials Register in a randomized and quasi-randomized controlled trial involving a comparison of partogram with no partogram, or comparison between different partogram designs. They concluded the routine use of partogram cannot be recommended for labour management and care and local institutional polices to be made regarding use of partogram. ${ }^{12}$ Mathibe-Neke J. M.in a study to decide whether a partogram is a labour management tool or just a midwifery record observed that despite the knowledge and skill to chart the graph and knowing the importance of partogram its applications in actual practice was less. ${ }^{12,13}$ Udeme Asibong has a similar finding lack of detailed knowledge of the partograph, poor staff, inadequate training are the factors which limit effective utilization of partogram. ${ }^{13}$ Claudia de Azevedo et al in their study in a Brazilian hospital observed that partogram was used mostly as a bureaucratic policy than for its actual value as a guiding tool. In this study, the partogram was used adequately but they did not find any difference between partogram and traditional model for monitoring labor, and sometime there were early interventions as dictated by a partogram ${ }^{14}$. This finding also coincides with our study, and they question the safety and efficacy of the too which allows unnecessary use of intervention depending on the findings of "alert" and "action" lines. Authors also observed that the partogram was used more beaurocratically -to complete the file: rather than as an instrument to be used for decision making. The original partogram has been revised many times, since 1990 WHO has published three different versions of partograms. The first partogram -the composite portogram included a latent phase of labor and active phase to begin at $3 \mathrm{~cm}$ cervical dilatation. This was successfully used for many years. ${ }^{6}$ This partogram was modified in 2000 to exclude latent phase and the plotting to begin after $4 \mathrm{~cm}$ dilatation. Recent ACOG guidelines suggest that the active phase should be considered after 6 $\mathrm{cm}$ dilatation. ${ }^{15}$ There is study by Mathibe-Neke JM, which wonders whether the partogram is a labour management tool or a midwifery record ? stating that it is not being utilized to the fullest in developing countries, despite respondents displaying reasonable understanding of and the importance of the use of the partograph in this study, there is evidence of limited use for it. ${ }^{16}$ Though proven to be very useful tool for monitoring labor partogram has undergone many transitions, can such a tool be considered 'standard' if it keeps changing? In a review study Carol Bedwell et al, voiced a concern about limitations in the use of partograph in the clinical context and the potential impact on its effectiveness, led them to conduct a systematic review of 95 papers on partogram, observed that despite being in use for so many years partogram did not reduce deaths by obstructed labour, it did not achieve its potential of recognizing the deviation of labour. The evidence of its effectiveness is inconclusive, a Cochrane review suggested that overall use of the partograph did not significantly impact on a number of specified outcome. ${ }^{17}$ Authors also, by our observation are doubtful of its effective use and application. The partogram was based on Friedman's labour curve, which has a doubtful validity today. The Friedman study was important at the time because it described labor in a way that had never been done before. Modern researchers have concluded that it can no longer be applied to contemporary practice. ${ }^{18}$ Too many things have changed since 1955. Epidurals have taken the place of sedation in labor; Pitocin is used much more frequently for both labor induction and augmentation; women today are older and tend to weigh more, and the forceps-with-episiotomy method is no longer routine practice. All of these factors can impact the length of labour. ${ }^{19}$ Paul Reuwer et al. in their discussion on 'Proactive support of labour' argue that the partographic representation of labour strongly affects the obstetricians' decision making. Filling in the partogram's minute details of foetal and maternal parameters distracts the sole 
purpose of relating progress of labour against time. They strongly advise against the use of WHO partogram. ${ }^{20}$ With so many conflicting views on the use of partogram for labour monitoring among researcher, which opinion is right? This brings home a novel question -is Partogram and Friedman's curve relevant today?

\section{CONCLUSION}

Philpott's partogram is a very visual and useful tool to monitor labors and detect labor abnormalities timely. Although it has served faithfully across the labor rooms in directing judiciously timed interventions in the event of labor abnormalities to avert foetal, maternal morbidity, for last 47 years, it is highly underutilized. There is a plethora of conflicting opinions regarding its utility in modern obstetrics today. Ranging from a complete faith in the tool to finding it obsolete and in need of a revision, to calling it a medicalization of a natural process. This may be due to the fact that human labor is not a mathematically calculable process and has individual variations of normality.

Funding: No funding sources

Conflict of interest: None declared

Ethical approval: Not required

\section{REFERENCES}

1. The Partograph: An Essential Tool for DecisionMaking during Labour, Best practice, Maternal and neonatal health, USAID, Baltimore, Maryland, JHPIEGO, Maternal and Neonatal Health Program, 2002 Sep.

2. Soni BL. Effect of Partogram Use on Outcomes for Women in Spontaneous Labour at Term: RHL Commentary. The WHO Reproductive Health Library. World Health Organization, Geneva. 2009.

3. Friedman EA. Primigravid labour. A graphic statistical analysis. Obstet Gynecol 1955;6: 567-89.

4. Philpott RH. Graphic records in labour. BMJ 1972; 4(5833):163-5.

5. World Health Organisation. World Health Organisation partograph in the management of labour. Lancet 1994;343(8910):1399-1404.

6. Magon N. Partogram revisited. Int J Clinic Cases Investigat. 2011;3(1):1-6.

7. Philpott RH, Castle WM. Cervicographs in the management of labour in primigravidae. II. The action line and treatment of abnormal labour. Int $\mathbf{J}$ Obstet Gynaecol.1972;79(7):599-60.

8. Kwast BE, Poovan P, Vera E, Kohls E. The modified WHO partograph: do we need a latent phase? Brit J Midwife. 2008;16(8):527-32.
9. Sam McCulloch, Friedman's Curve - How It's Used During Labour. 2016

10. Zhang JL, Troendle JF, Yancey MK. Reassessing the labor curve in nulliparous women. Am J Obstet Gynecol. 2002;187(4):824-8.

11. Zhang J, Landy HJ, Branch DW, Burkman R, Haberman S, Gregory KD et al. Contemporary Patterns of Spontaneous Labor with Normal Neonatal Outcomesfor the Consortium on Safe Labor. Obstet Gynecol. 2010;116(6):1281-87

12. Lavender T, Hart A, Smyth RM. Effect of partogram use on outcomes for women in spontaneous labour at term. Cochrane database of systematic reviews. 2013(7).

13. Asibong U, Okokon IB, Agan TU, Oku A, Opiah M, Essien EJ et al. The use of the partograph in labor monitoring: a cross-sectional study among obstetric caregivers in General Hospital, Calabar, Cross River State, Nigeria. International J Women's Health. 2014;6:873.

14. de Azevedo Aguiar C, Gonçalves R, Tanaka AC. Use of the partogram in labor: analysis of its application in different care models. Open J Obstet Gynecol. 2013;3(09):1.

15. Caughey AB, Cahill AG, Guise JM, Rouse DJ, American College of Obstetricians and Gynecologists. Safe prevention of the primary cesarean delivery. Am J Obstetrics and Gynecol. 2014;210(3):179-93.

16. Mathibe-Neke JM, Lebeko FL, Motupa B. The partograph: A labour management tool or a midwifery record?. Int $\mathrm{J}$ Nursing Midwife. 2013;5(8):145-53.

17. Bedwell C, Levin K, Pett C, Lavender DT. A realist review of the partograph: when and how does it work for labour monitoring?. BMC Pregnancy Childbirth. 2017;17(1):31.

18. Rebecca Dekker. Friedman's Curve and Failure to Progress: A Leading Cause of Unplanned Cesareans. Evidence Based Birth; 2013.

19. Laughon SK, Zhang J, Grewal J, Sundaram R, Beaver J, Reddy UM. Induction of labor in a contemporary obstetric cohort. Am J Obstet Gynecol. 2012 ;206(6):486-e1.

20. Reuwer P, Bruinse H, Franx A. Proactive support of labor: the challenge of normal childbirth. Cambridge University Press; 2009.

Cite this article as: Choudhary A, Tanwar M.

Partogram and its relevance in modern obstetrics. Int J Reprod Contracept Obstet Gynecol 2019;8:1500-4. 